\title{
Impact of emergency room meetings on improvement of door-to-needle times in acute ischemic stroke patients: A single center's experience
}

\author{
(1) Bilgehan Atilgan Acar \\ Department of Neurology, Sakarya University Faculty of Medicine, Sakarya, Turkey
}

\begin{abstract}
OBJECTIVE: One major limitation of the use of intravenous tissue plasminogen activator (IV-tPA) is the short treatment window of acute ischemic stroke (AIS). In this article, we analyze the impact of emergency room meetings on step-by-step improvement of door-to-needle times (DTN).

METHODS: This study used prospectively recorded data of AIS patients treated with IV-tPA admitted to the Sakarya University Education and Research Hospital between January 2015 and August 2017. Time benchmarks of DTN were recorded on a case-by-case basis. Meetings were held in the emergency room if there was an increase of more than $25 \%$ in DTN of subsequent AIS patients treated with IV-tPA. Guideline-recommended stroke management methods and feedback from our previous DTN data were both considered. The goal was to improve DTN within 60 minutes for at least $50 \%$ of AIS patients.

RESULTS: Mean DTN of 20 patients was $76.9 \pm 32.4$ minutes. Nine patients experienced $\leq 60$ minute DTN times, while two were under 30 minutes. Six meetings were conducted, with two each in 2015, 2016, and 2017. Without exception, there was a reduction in DTN after all meetings. Considering the intervals of the six meetings, the ratios of patients treated at $\leq 60$ minutes were $0 \%, 0 \%, 60 \%, 66.6 \%, 40$ and $100 \%$, respectively.
\end{abstract}

CONCLUSION: Meetings in the emergency room, when conducted according to certain rules, can be effective in improving DTN.

Keywords: Acute stroke; door-to-needle time; emergency room.

Cite this article as: Acar BA. Impact of emergency room meetings on improvement of door-to-needle times in acute ischemic stroke patients: A single center's experience. North Clin Istanb 2018;5(4):282-287.

troke is a leading cause of death and disability worldwide. Ischemic stroke is the most common type. Eligible patients presenting with acute ischemic stroke (AIS) are treatable via intravenous tissue plasminogen activator (IV-tPA) if the stroke is recognized early (up to 4.5 hours after symptom onset). Rapid treatment with IV-tPA with a specialized team improves recovery in patients with AIS [1].

This short time window is a major limitation to the benefits of IV-tPA and American Heart Association
(AHA)/American Stroke Association (ASA) Stroke Council recommendations of a door-to-needle time (DTN) of $\leq 60$ minutes [2]. Although great importance is placed on improving the DTN in 60 minutes or less, fewer than one-third of AIS patients receiving IV-tPA are treated within this time [3]. This time target for treatment was later included in the AHA's guidelines and has remained a metric in hospitals identified as primary or comprehensive stroke centers [4]. Emergency room (ER) crowding and frequent changes and rotations of

Received: September 08, 2017 Accepted: December 25, 2017 Online: September 10, 2018

Correspondence: Dr. Bilgehan Atilgan ACAR. Sakarya Universitesi Tip Fakultesi, Noroloji Anabilim Dali, Sakarya, Turkey.

Tel: +90 5056579170 e-mail: bilgehanacar@hotmail.com

(c) Copyright 2018 by Istanbul Provincial Directorate of Health - Available online at www.northclinist.com 
emergency room doctors are the major obstacles to this goal. In order to overcome this problem, our stroke team held ER meetings if the DTN of subsequent patients exceeded $25 \%$. The aim of these meetings was to improve DTN via education and motivation.

In Turkey, rt-PA for treatment of acute ischemic stroke has been permitted by the Ministry of Health since 2006. The relatively late approval of use of IVtPA has resulted in obvious underuse of treatment [5]. Thrombolytic therapy in acute ischemic stroke is estimated to be at lower levels [6] than it should be, and the data are not sufficient in this regard. Very few studies have been reported on this issue [5, 7-11], many of which evaluated clinical outcomes of patients. However, the DTN have not been reviewed in detail.

Our aim is to evaluate the DTN of all patients treated with IV-tPA in acute ischemic stroke in our hospital and to investigate the effect of the emergency room stroke meetings that organized by the stroke team in shortening this period.

\section{MATERIALS AND METHODS}

Twenty AIS patients who were treated with IV-tPA within 4.5 hours at Sakarya University Education and Research Hospital from January 2015 to August 2017 were admitted to the study. All the data in the study were obtained from hospital records and a stroke information database maintained progressively by the stroke neurologist.

\section{Assessment of the patient in an emergency room}

After entering the emergency gate, all patients suspected to be undergoing AIS were initially evaluated by an ER doctor. This period of time was expressed as "door to doctor". After taking medical history, time last known well, symptom onset, vital assessment, fingertip glucose, and ordering laboratory work, patients underwent a head CT. If symptoms had begun within 4.5 hours, the ER doctor informed the stroke team neurologist. This period of time was expressed in terms of "access to neurologic expertise \& laboratory /CT scan order". ECG was performed before or after CT scan completion. After CT scan interpretation and laboratory results, the neurologist evaluated the eligibility of patients for IV-tPA treatment. Prior to administration of IV-tPA, patient condition was stabilized, especially if elevated blood pressure, a urinary catheter, and/or second vascular access were present. Administration of bolus dose began in the ER after the patient completed an informed consent form.
The time period from the emergency gate to first bolus injection was expressed as "door to needle time" (DTN).

\section{Educational and motivational meetings}

The first meeting was held on 07 January 2015 in the Neurology Department with the participation of stroke team, consisting of neurology, emergency medicine, radiology, and cardiology doctors. The following five meetings were held in the emergency room if there was more than a $25 \%$ increase in DTN in subsequent AIS patients. The subjects of these meetings included acute ischemic stroke management, and our previous timeline metrics of DTN. Short presentations were used referring to guideline-recommended stroke management and focused attention on what we had done and what we could have done to improve DTN in our previous patients using feedback from our previous DTN data. The goal was to improve DTN within 60 minutes for at least $50 \%$ of acute ischemic stroke patients.

Ethical approval was obtained from the Sakarya University Faculty of Medicine Ethics Committee in order to conduct the study.

\section{RESULTS}

Twenty AIS patients who received IV rt-PA between January 2015 and August 2017 were analyzed. Mean DTN was $76.9 \pm 32.4$ minutes. Nine patients experienced $\leq 60$ minutes of DTN, which was our goal, while only two were $\leq 30$ minutes. After the initial meeting in the Neurology Department on 07 January 2015, five additional meetings were held due to a $25 \%$ increase in DTN in the emergency room. One meeting was held in 2015, two in 2016, and two in 2017 (Fig. 1).

The first patient was treated with IV rt-PA about three and a half months after the first meeting with a DTN of 135 minutes. The second patient's DTN was 75 minutes. When DTN extended to 155 minutes in the third patient (which was more than $100 \%$ range of the previous one), we held the second meeting. The fourth patient's DTN was improved to 95 minutes. The durations of DTN in the $6^{\text {th }}, 7^{\text {th }}$ and $8^{\text {th }}$ patients were 95,100 , and 83 , respectively (Fig. 1).

Due to the prolongation of the $9^{\text {th }}$ patient's DTN to 107 minutes (which was more than $25 \%$ range of the previous one), a third meeting was held. After the third meeting, the DTNs of the $10^{\text {th }}, 11^{\text {st }}, 12^{\text {nd }}$, and $13^{\text {rd }}$ patients were $55,53,64$, and 28 minutes respectively. 
- Door to doctor

- Access to neurologic expertise \& Laboratory/CT scan order

- CT scan completion

- CT scan interpretation/Laboratory results

- DNT (door to needle time) (door to treatment)

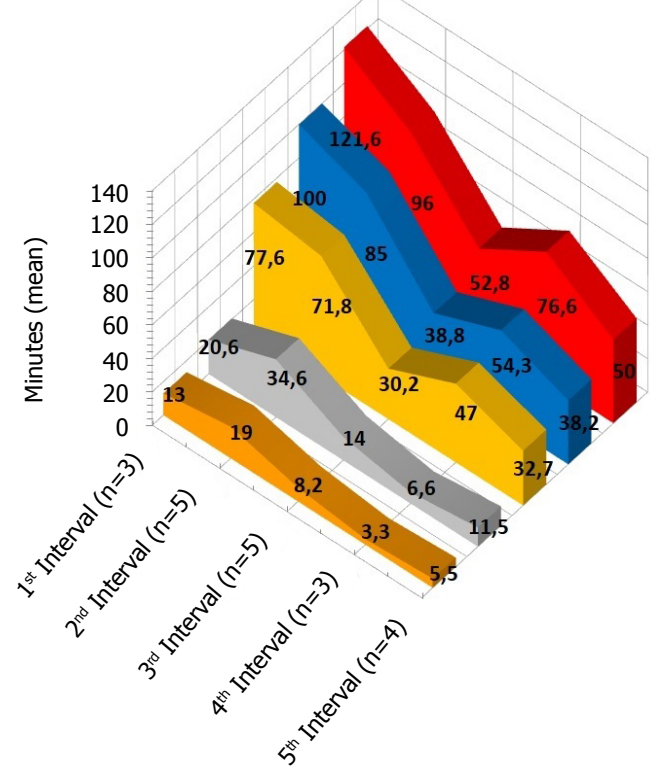

FIGURE 1. Mean stroke evaluation time benchmarks and door-to-needle times (DTN) of AIS patients at meeting intervals.
The shortest DTN was obtained with 28 minutes for the $12^{\text {nd }}$ patient, which was a record low DTN duration. But this success did not continue, as the DTN of the $13^{\text {rd }}$ patient was prolonged to 64 minutes (more than $25 \%$ longer than the previous). We thus held a fourth meeting (Fig. 1).

After the fourth meeting, the DTNs of the $14^{\text {th }}, 15^{\text {th }}$ and $16^{\text {th }}$ patients were 59,56 , and 115 minutes, respectively. The increase in DTN between the $15^{\text {th }}$ and $16^{\text {th }}$ patients was $105.3 \%$, after which a fifth meeting was held (Fig. 1).

After the fifth meeting, 4 patients (the $17^{\text {th }}, 18^{\text {th }}, 19^{\text {th }}$ and $20^{\text {th }}$ patients) received thrombolytic therapy with DTN of $60,60,30$ and 50 minutes respectively. Finally, a sixth meeting was held due to $66.6 \%$ elongation of DTN for the last two patients (Fig. 1).

Without exception, there was reduction in DTN times after all meetings. Details of the DTNs including timelines of the 20 patients and the dates of the 6 meetings are shown in Figure 1. Mean changes in the duration of DTN for each interval are shown in Figure 2.

Considering the meeting intervals among the six meetings, the ratios of patients treated in $\leq 60$ minutes were $0 \%, 0 \%, 60 \%, 66.6 \%$, and $100 \%$, respectively (Table 1 ).

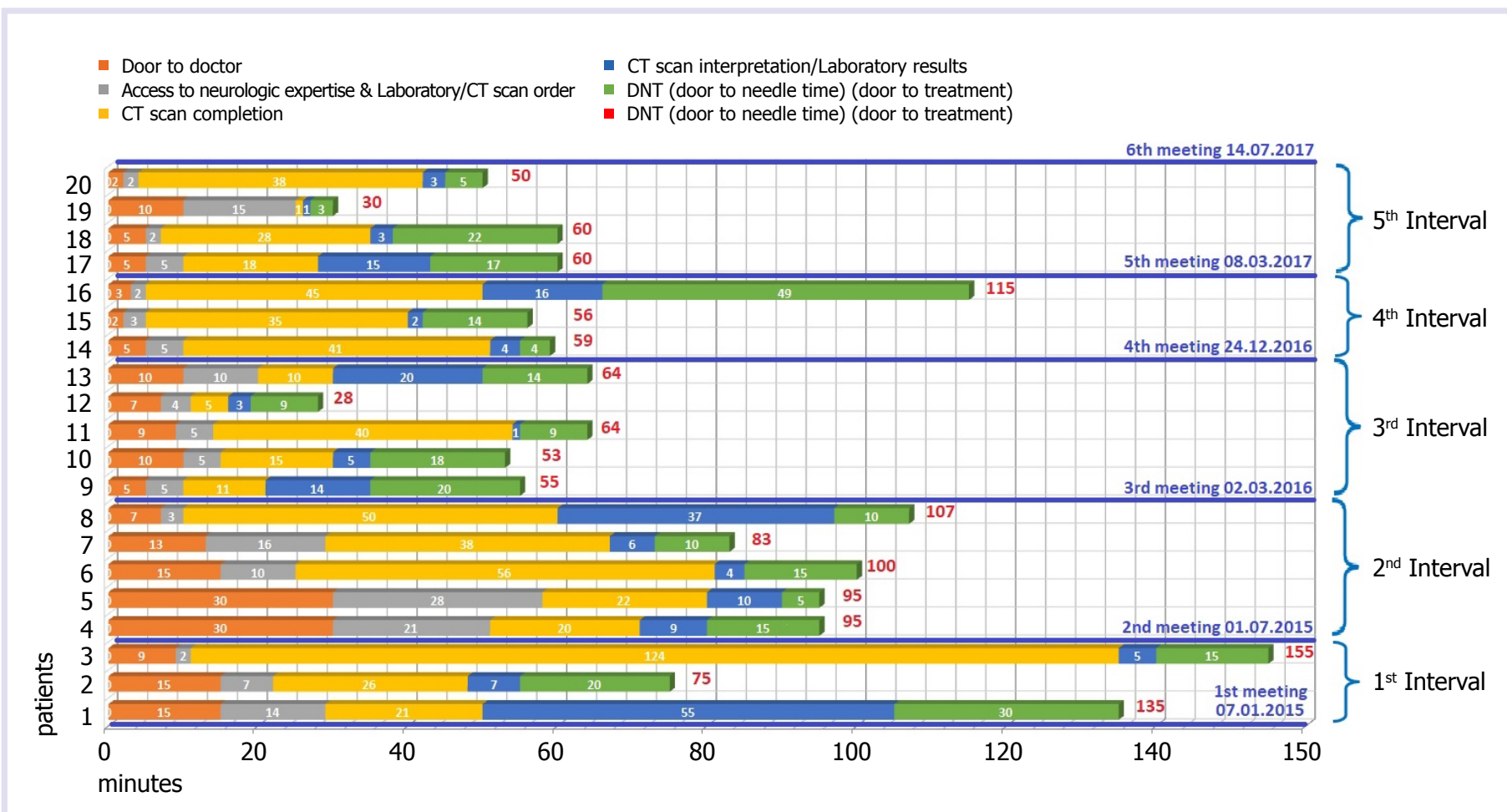

FIGURE2. Door-to-needle times (DTN) with stroke evaluation time benchmarks of 20 AIS patients and timedates of the meetings. 


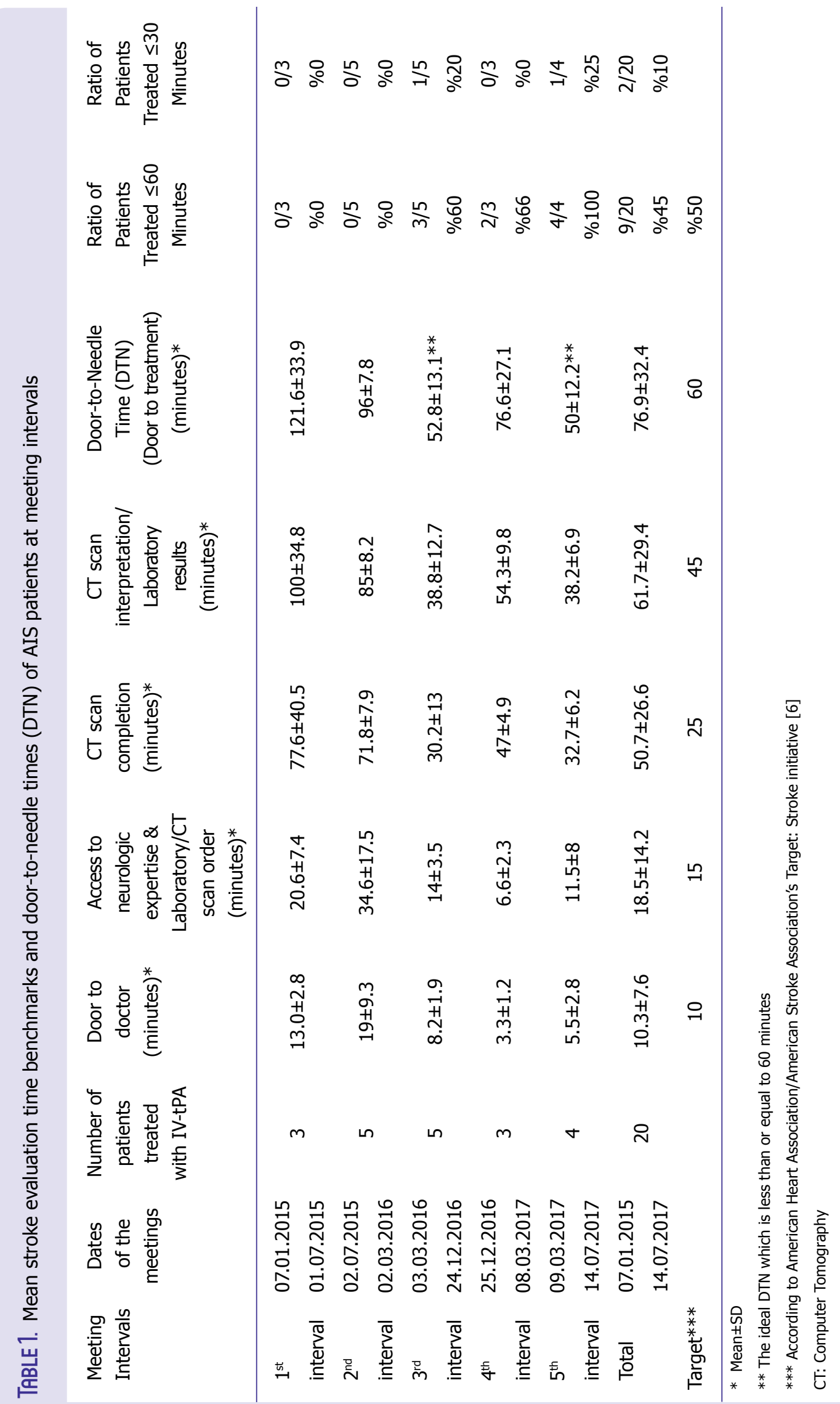




\section{DISCUSSION}

Thrombolysis with IV-tPA is one of the most important reperfusion strategies that improves functional outcome after acute ischemic stroke. It is a first-line treatment worldwide [12]. A major goal in the treatment of acute ischemic stroke is the rapid improvement of blood flow. Every minute is golden to perform treatment without sequelae, as each minute 1.9 million neurons with 14 billion synapses are destroyed [13]. In hospitals with very busy emergency departments and high patient loads, these precious minutes can be wasted. Our hospital is the most central and comprehensive in Sakarya province, with an average of 30.000 patients admitted per month. At this intensity, catching treatable acute stroke patients requires more effort. The most important task of the hospital stroke team is to treat the AIS diagnosed patient as soon as possible when admitted to the hospital.

Many studies have been published that consider the prevention of DTN delays for AIS patients. Fonarow et al. [3] demonstrated that fewer than one third of tPA receiving acute ischemic stroke patients are treated within guideline-recommended door-to-needle time. This demonstrates the a need for a targeted initiative to improve the timeliness of reperfusion in acute ischemic stroke. Following this, a national initiative known as Target: Stroke was established [14]. It was conceived in November 2009 by the American Heart Association/American Stroke Association in partnership with other organizations to increase the proportion of IV-tPA-treated patients who achieve guideline recommended door-to-needle time ( $\leq 60$ minutes) for at least $50 \%$ of acute ischemic stroke patients with the following strategies: emergency medical service prenotification; a single call to activate the stroke team; rapid completion and interpretation of brain imaging; using specific protocols and 155 tools; premixing tPA; a team-based approach; and rapid data feedback [14]. Similar programs have been reported to improve DTN for AIS patients. Bhatt et al. [15] also highlighted strategies such as emergency medical service prenotification, activating the stroke team with a single call, rapid acquisition and interpretation of brain imaging, use of specific protocols and tools, premixing tPA, a team-based approach, and rapid data feedback. Thortveit et al. [16] reported that starting treatment in CT laboratory instead of emergency room contributed to reduced DTN. Tveiten et al. [17] reported that even an inexperienced stroke center can provide the necessary logistics for thrombolytic therapy, with short hospital delays to a large proportion of patients with acute stroke. They found that prenotification of a team and the initiation of thrombolytic treatment in the emergency room are the most important factors. Schrock et al. [18] reported that an ECG or a chest radiograph obtained before head CT increased CT times by 6 and 13 minutes, respectively, in AIS patients.

Extensive work concerning this topic remains limited in Turkey. Öztürk et al. [7] published outcomes of 21 acute ischemic stroke patients who had undergone IV-tPA treatment between 2006 and 2008, but did not address the patient's DTN. They emphasized that this practice is within a narrow treatment window and that well-equipped centers are needed. Tanriverdi et al. [8] emphasized that they obtained successful results in accordance with the literature, with 15 patients who took this treatment between 2006 and 2012. Their mean reported DTN was 82.5 (45-145) minutes. Sorgun et al. [9] reported 32 patients who had received IV-tPA treatment between 2007 and 2012, with a mean DTN of $85 \pm 37$ (15-165) minutes. They emphasized that the sooner treatment begins, the more positive the results. Oruç et al. [10] reported the data of 40 patients who received IV-tPA treatment between 2011-2015 in a university hospital, and highlighted that the treatment was reported to be safe and effective, as well as to reduce disability at the end of the third month. However this did not address the DTN data of the patients. In a more recent study, Kunt [11] reported the clinical outcome data of 25 patients who received IV-tPA treatment within 2.5 years from 2014 in a state hospital, and the mean DTN was $70 \pm 40(20-195)$ minutes.

Kutluk et al. [5] published the first and only nationwide registry on thrombolysis after the approval of IVtPA for the treatment of acute ischemic stroke in Turkey. This prospective multicenter hospital-based cohort study from 38 centers in 18 cities from 2006 to 2013 highlighted that the critical time limit of DTN, which is recommended to be 60 minutes, was reached at the end of the fourth year of the registry and despite the addition of new centers, the mean treatment time remained at 69 minutes. In this study, relationship between clinical experience and DTN were evaluated. "High-volume center" was defined as a center applying IV-tPA to 10 or more patients per year, while "low-volume center" was defined as a center applying IV-tPA to fewer than 10 patients per year. Authors reported that although the DTN durations of the high-volume centers were higher than low-volume centers initially, at the end of the study high-volume centers had better outcome for hemorrhage and DTN. Furthermore, they highlighted that this expe- 
rience is also associated with decreased mortality. From this point of view, our center is a low-volume center. However, unlike others, DTN of our patients tended to decrease by year. This could be due to our emergency room meetings held to reduce the DTN.

To decrease DTN after each period of meetings, we implemented these precautions:

1. Creating a stroke team with neurology, emergency medicine, radiology, and cardiology doctors. This includes using established specific protocols and guideline based algorithms, order sets, dosing charts and activating the stroke team with a smartphone application and recording detailed data of the patients prospectively and analyze them on further meetings;

2. Holding meetings in emergency room with the participation of emergency room doctors; and

3. Broadening the participation profile with emergency medical service staff and all newly-assigned or rotational emergency room doctors.

\section{Conclusion}

In addition to the effects of each factor summarized above, in our study two meetings were held each year. All meetings corresponded to the first and last half of each year. It may be concluded that educational and motivational meetings must be held biannually with regularity (at least twice a year). Educational and motivational meetings held in the emergency room are beneficial in improving DTN when repeated within a specified framework.

Acknowledgement: I am thankful to my colleagues Semra Alacam Koksal, Turkan Acar, Aybala Neslihan Alagoz, Yesim Guzey Aras, Murat Yucel, Yusuf Yurumez, Alper Karacan, Ramazan Akdemir, Ayhan Boluk who provided expertise that greatly assisted the research.

Conflict of Interest: No conflict of interest was declared by the authors.

Financial Disclosure: The authors declared that this study has received no financial support.

\section{REFERENCES}

1. Saver JL, Levine SR. Alteplase for ischaemic stroke-much sooner is much better. Lancet 2010;375:1667-8. [CrossRef]

2. Adams HP Jr, del Zoppo G, Alberts MJ, Bhatt DL, Brass L, Furlan A, et al. Guidelines for the early management of adults with ischemic stroke: a guideline from the American Heart Association/American Stroke Association Stroke Council, Clinical Cardiology Council, Cardiovascular Radiology and Intervention Council, and the Atherosclerotic Peripheral Vascular Disease and Quality of Care Outcomes in
Research Interdisciplinary Working Groups: The American Academy of Neurology affirms the value of this guideline as an educational tool for neurologists. Circulation 2007;115:e478-534. [CrossRef]

3. Fonarow GC, Smith EE, Saver JL, Reeves MJ, Bhatt DL, Grau-Sepulveda MV, et al. Timeliness of tissue-type plasminogen activator therapy in acute ischemic stroke: patient characteristics, hospital factors, and outcomes associated with door-to-needle times within 60 minutes. Circulation 2011;123:750-8. [CrossRef]

4. Jauch EC, Saver JL, Adams HP Jr, Bruno A, Connors JJ, Demaerschalk BM, et al. Guidelines for the early management of patients with acute ischemic stroke: a guideline for healthcare professionals from the American Heart Association/American Stroke Association. Stroke 2013;44:870-947. [CrossRef]

5. Kutluk K, Kaya D, Afsar N, Arsava EM, Ozturk V, Uzuner N, et al. Analyses of the Turkish National Intravenous Thrombolysis Registry. J Stroke Cerebrovasc Dis 2016;25:1041-1047. [CrossRef]

6. Kutluk K. Akut iskemik inmede intravenöz trombolitik tedavi: sorumluluğumuzun farkında mıyız? Türk Beyin Damar Hastalıkları Dergisi 2009:15:35-9.

7. Öztürk V, Yaka E, Uğurel B, Poyraz T, Men S, Kutluk K. Intravenous Thrombolysis in Acute Ischemic Stroke: Experiences in Dokuz Eylül University Hospital, Medical Faculty, Department of Neurology. J Neurol Sci [Turk] 2008;25:75-83.

8. Tanrıverdi Z, Örken DN, Aksoy S, Yükselen NP, Karg 1 EÖ, Mumcu S, et al. Intravenous thrombolytic theraphy in acute stroke: the experience of the neurology department of sisli etfal education and research hospital. Medical Bulletin of Sisli Etfal Hospital 2012;46:165-9.

9. Sorgun MH, Işı1kay CT. Akut İskemik İnmede İntravenöz Trombolitik Tedavi. Ankara Üniversitesi Tıp Fakültesi Mecmuası 2012;65:103-106

10. Oruç S, Demirbaş H, Yaman M, Yılmaz Küsbeci Ö, Akpınar Oruç $\mathrm{O}$, Tünay K, et al. Intravenous Thrombolytic Treatment Experiences In Patients With Acute Ischemic Stroke at The University of Kocatepe, Neurology Clinics. Türk Beyin Damar Hastalıkları Dergisi 2015;21:189-93. [CrossRef]

11. Kunt R. Bir devlet hastanesi bakiş açisiyla akut iskemik inmede intravenöz trombolitik tedavi. Türk Beyin Damar Hastalıkları Dergisi 2016;22:91-9. [CrossRef]

12. Wahlgren N, Ahmed N, Dávalos A, Ford GA, Grond M, Hacke W, et al. Thrombolysis with alteplase for acute ischaemic stroke in the Safe Implementation of Thrombolysis in Stroke-Monitoring Study (SITSMOST): an observational study. Lancet 2007;369:275-82. [CrossRef]

13. Saver JL. Time is brain-quantified. Stroke 2006;37:263-6. [CrossRef]

14. Fonarow GC, Smith EE, Saver JL, Reeves MJ, Hernandez AF, Peterson $\mathrm{ED}$, et al. Improving door-to-needle times in acute ischemic stroke: the design and rationale for the American Heart Association/American Stroke Association's Target: Stroke initiative. Stroke 2011;42:2983-9.

15. Bhatt A, Shatila A. Neurohospitalists Improve Door-to-Needle Times for Patients With Ischemic Stroke Receiving Intravenous tPA. Neurohospitalist 2012;2:119-122. [CrossRef]

16. Thortveit ET, Bøe MG, Ljøstad U, Mygland A, Tveiten A. Organizational changes aiming to reduce iv $\mathrm{tPA}$ door-to-needle time. Acta Neurol Scand 2014;130:248-52. [CrossRef]

17. Tveiten A, Mygland A, Ljøstad U, Thomassen L. Intravenous thrombolysis for ischaemic stroke: short delays and high community-based treatment rates after organisational changes in a previously inexperienced centre. Emerg Med J 2009;26:324-6. [CrossRef]

18. Schrock JW, Lum M. Drill down analysis of door-to-needle time of acute ischemic stroke patients treated with intravenous tissue plasminogen activator. Am J Emerg Med 2014;32:1330-3. [CrossRef] 